\title{
A Internet como Novo Meio de Comunicação para os Destinos Turísticos: $O$ caso da Ilha da Madeira*
}

\author{
The Internet as new medium communication for the destinations: \\ Madeira Island case study
}

\author{
Maria Noémi Nunes Vieira Marujo ${ }^{1}$
}

\begin{abstract}
Resumo
Com o aparecimento da Internet, assiste-se cada vez mais ao nascimento e desenvolvimento de novos destinos turísticos. O novo meio de comunicação faz com que os consumidores aumentem os seus patamares de exigências e de expectativas. Ao poder público e às empresas privadas cabe-lhes o papel de sensibilizar o imaginário dos turistas para visitarem as suas comunidades e regiões e não outras. O presente artigo pretende analisar a importância que o poder local e regional da Madeira atribui à Internet para a divulgação dos seus municípios como destinos turísticos a serem fruídos. A pesquisa foi baseada em entrevistas e análise dos sites municipais. O trabalho de campo realizou-se de Janeiro de 2004 a Junho de 2004. Este artigo centra-se essencialmente na análise das entrevistas e está estruturado nos seguintes tópicos: Introdução à problemática; fundamentação teórica sobre a temática; análise das entrevistas e conclusão.
\end{abstract}

Palavras-chave: turismo; Internet; novo consumidor; promoção; informação.

\begin{abstract}
With Internet new tourism destinations are promoted and developed. That communication medium generates and increases the consumers' demands and expectations. Local and regional government bodies and private companies both play a new role: through Internet they should be able to feed the tourist's imaginary in order to choose their communities and regions instead of others. This article analyses the importance that local and regional authorities attribute to new technologies for promoting their municipalities as tourism destinations. The research was based on interviews and analysis of web sites. The fieldwork has been done from January 2004 to June 2004. This article mainly approaches the interviews analysis and it is structured in the following topics: Introduction; theoretical approach, interviews analysis and conclusion.
\end{abstract}

Keywords: tourism; Internet; new consumer; promotion; information.

\footnotetext{
* O presente artigo corresponde a uma parte da dissertação intitulada “Turismo: Meios de Comunicação e Promoção. O Caso da Madeira”, do Mestrado em Sociologia na Universidade de Évora.

${ }^{1}$ Licenciada em Comunicação Social, Mestre em Sociologia e Doutoranda em Turismo na Universidade de Évora. Docente de Turismo e Comunicação na Universidade de Évora (Portugal). Endereço: Estrada de Reguengos 426 R/C 7000 Évora - Portugal. E-mail: noemi@uevora.pt
} 


\section{Introdução}

O turismo é considerado, actualmente, uma das maiores seduções dos tempos modernos e, por isso, faz parte da nossa sociedade de consumo. Os meios de comunicação, ao divulgarem espaços paradisíacos para serem contemplados, exercem um papel fundamental nesse acto de consumo. Elaboram imagens sobre diversos lugares e povos, incentivando cada vez mais o desejo pela viagem. O potencial turista, seduzido por essa propaganda, envolve-se num mundo de sonhos e, como quer escapar por alguns dias à sua rotina diária, procura realizar as suas fantasias ou desejos nas promessas difundidas pelos meios de comunicação. O turista tem como primeira intenção conhecer um local que o satisfaça e, na maior parte das vezes, procura um destino completamente diferente da sua zona de origem, o que significa ter acesso a um conjunto de informações sobre os elementos que compõem a oferta turística de uma localidade. Normalmente, a distribuição desse material promocional é feita através dos meios de comunicação. “Os meios de comunicação são um instrumento que, uma vez bem utilizado, pode levar as entidades públicas do turismo e o sector privado a atingir os seus objectivos promocionais: divulgar, motivar e causar impacto” (MARUJO, 2004, p.11). De facto, a forma pela qual a imagem de uma região é divulgada, através dos meios de comunicação, é fundamental para a decisão de escolha do turista. Pois, na selecção de um destino, ele baseia a sua escolha não só num ou outro relato de um amigo, parente ou especialista, mas também na informação veiculada pelos meios de comunicação. Na maior parte das vezes, eles são os «olhos» e os «ouvidos» do viajante.

Sheldon (1993) afirma que a informação é a “alma” do turismo, sem a qual o sector não funciona. Ou seja, o turismo não sobrevive sem a informação e, por isso, precisa de estar ao lado dos meios de comunicação. Assim, a decisão de um turista real ou potencial «comprar» um destino, ou seja visitá-lo, depende em grande parte da informação que é oferecida ao turista pelos meios de comunicação. Hoje, o consumidor de turismo está cada vez mais exposto a um fluxo maior de informações veiculadas, principalmente, pelos meios de comunicação. O ser humano quer conhecer novos lugares e quotidianos diferentes do seu. Os estímulos atribuídos pelos meios de comunicação são decisivos para que as informações de outros destinos despertem a curiosidade e o interesse em viajar. No núcleo deste processo de mudança e exigência do consumidor está a Internet, que permite a troca de informações instantaneamente entre quase todos os pontos do planeta e a comunicação directa entre pessoas. De facto, e como salienta Buhalis (2000), a revolução das tecnologias de informação 
teve implicações profundas para a gestão da indústria turística, porque alterou a competitividade das organizações e dos destinos turísticos.

A actividade turística, na Madeira, é considerada por muitos como a tábua de salvação para o desenvolvimento da região. O turismo, graças à sua importância económica e social, é um importante pilar para a economia e desenvolvimento desta ilha, dado que constitui um mercado de excelência para os produtos locais. Torna-se, assim, o sector com mais peso na economia regional, arrastando consigo uma quantidade de actividades, quer comerciais, quer de serviços bastante relevantes. Contudo, para que haja um maior desenvolvimento e crescimento da actividade turística é necessário captar potenciais turistas. Aqui, os municípios devem ter um papel determinante na promoção do seu território como um destino turístico. Neste âmbito, devem preocupar-se em promover a sua região criando, de certa forma, uma imagem positiva da área, pelo qual são responsáveis, como uma boa zona para praticar turismo. Saliente-se que a promoção não se baseia apenas na divulgação de uma localidade ou região em feiras e eventos. É necessário fazer, também, difusão desses destinos turísticos nos meios de comunicação.

Com o desenvolvimento da Internet assiste-se cada vez mais ao nascimento e desenvolvimento de destinos turísticos. O despertar da Internet fez com que, ao nível da promoção, passasse a existir uma maior competitividade entre os destinos turísticos. Assistese, cada vez mais, a um aumento da concorrência entre os destinos turísticos, sejam eles de país para país ou de região para região. E, por isso, passou a existir por parte das organizações promotoras uma maior preocupação em projectar uma imagem favorável dos seus destinos turísticos. Actualmente, e devido à Internet, um turista que pretenda conhecer o património ou a cultura de uma região tem, por exemplo, opções de ir para outras regiões com essas mesmas características. Portanto, quem possuir melhor estratégia de comunicação terá maiores vantagens na opção desse turista, uma vez que lhe transmite uma segurança maior na satisfação dos seus desejos.

Com a Internet, o turista tem acesso a um conjunto de informações sobre um determinado país, região, ou localidade que antes não tinha: Atracções turísticas, serviços públicos, infraestruturas, endereços, serviços turísticos, etc. As imagens persuasivas, a informação, as mensagens publicitárias sobre uma determinada localidade, disponibilizadas na Internet, aumentam a curiosidade do turista sobre os destinos a conhecer. Num mundo cada vez mais globalizado e marcado por um aumento significativo da competitividade, as organizações promotoras do turismo necessitam de estar cada vez mais próximas dos consumidores. Por 
isso, a Internet surge como um novo campo de batalha para os promotores dos destinos turísticos. Actualmente, se um destino não figura na Internet pode correr o risco de dar lugar a que o turista real ou potencial opte por outro destino.

A problemática detectada aponta para as seguintes questões: Qual é o papel do poder local e regional da Madeira na divulgação dos municípios, via Internet, como um destino turístico? Qual é a importância que o poder local e regional da Madeira atribui à Internet para a promoção dos seus destinos? Que elementos turísticos são mais valorizados pelo poder local e regional para persuadir o turista a visitar a sua região e não outra? Assim, a investigação teve como principal objectivo: Identificar o contributo do poder local e regional madeirense na divulgação turística dos seus municípios, via Internet.

Tendo como objecto de estudo o papel dos municípios da Ilha da Madeira e da Direcção Regional do Turismo (DRT) na divulgação turística das suas localidades, via Internet, optouse pelo delineamento de uma estratégia metodológica baseada no estudo de caso. A opção por esta estratégia de análise deve-se ao facto de ela facultar ao investigador "a possibilidade de se concentrar num caso específico ou situação e de identificar, ou tentar identificar, os diversos processos interactivos em curso” (BELL, 1997, p. 23).

Quadro I - Guião de Entrevista à DRT

\begin{tabular}{|c|c|c|}
\hline Assunto & Objectivos & Questões \\
\hline I - Promoção & $\begin{array}{l}\text { - Identificar dos elementos que } \\
\text { compõem a oferta turística quais os que } \\
\text { são considerados mais importantes para } \\
\text { a promoção da região como um destino } \\
\text { turístico }\end{array}$ & $\begin{array}{l}\text { 1- Dos elementos que compõem a oferta } \\
\text { turística qual ou quais considera ser (em) } \\
\text { o(s) mais importante (s) para a } \\
\text { propaganda da ilha como um destino } \\
\text { turístico? Porquê? }\end{array}$ \\
\hline $\begin{array}{l}\text { II- Meios de } \\
\text { Comunicação }\end{array}$ & $\begin{array}{l}\text { - Averiguar quais os meios de } \\
\text { comunicação que a DRT utiliza para } \\
\text { promover a imagem da Madeira como } \\
\text { um destino turístico, e qual considera } \\
\text { ser o mais importante } \\
\text { - Verificar a importância que a DRT dá } \\
\text { à Internet para a promoção da sua } \\
\text { região como um destino a visitar }\end{array}$ & $\begin{array}{l}\text { 1- Que meios de comunicação é que a } \\
\text { DRT usa para promover a imagem da } \\
\text { Madeira com um destino turístico? } \\
\text { 2- Qual considera ser o meio de } \\
\text { comunicação mais importante para a } \\
\text { promoção? Porque? } \\
\text { 3- Que importância dá à Internet para a } \\
\text { promoção da Ilha como um destino a } \\
\text { visitar }\end{array}$ \\
\hline $\begin{array}{l}\text { II- Direcção Regional do } \\
\text { Turismo (DRT) }\end{array}$ & $\begin{array}{l}\text { - Avaliar o papel da DRT na promoção } \\
\text { dos municípios como destinos turísticos }\end{array}$ & $\begin{array}{l}\text { 1- Como é que a DRT promove os } \\
\text { municípios madeirenses como destinos } \\
\text { turísticos a serem consumidos? }\end{array}$ \\
\hline
\end{tabular}

Na investigação, para além da pesquisa bibliográfica, optou-se pela técnica da entrevista. A entrevista, entendida como um procedimento de recolha de informação que utiliza a forma da 
comunicação verbal (ALMEIDA e PINTO, 1995), foi uma técnica crucial para a investigação, na medida em que permitiu “explorar determinadas ideias, testar respostas, investigar motivos e sentimentos...” (BELL, 1997, p. 118). Assim, para atingir o objectivo da investigação, optou-se pela entrevista semi-directiva. A entrevista semi-directiva foi aplicada ao Director Regional do Turismo e aos Presidentes dos Municípios Madeirenses. De forma a apoiar o investigador na recolha da informação, construiu-se um modelo para as entrevistas aos presidentes dos municípios da Ilha da Madeira (aplicadas em Janeiro e Fevereiro de 2004) e outro para a entrevista ao presidente da DRT (aplicada em Março de 2004).

Quadro II - Guião da Entrevista aos Responsáveis dos Municípios da Madeira

\begin{tabular}{|c|c|c|}
\hline Assunto & Objectivos & Questões \\
\hline I - Promoção & $\begin{array}{l}\text { - Identificar dos elementos que compõem a } \\
\text { oferta turística quais os que são } \\
\text { considerados mais importantes pelo poder } \\
\text { local para a promoção do seu município } \\
\text { como um destino turístico }\end{array}$ & $\begin{array}{l}\text { 1- Dos elementos que compõem a } \\
\text { oferta turística qual ou quais } \\
\text { considera ser (em) o(s) mais } \\
\text { importante (s) para a propaganda do } \\
\text { seu município como um destino } \\
\text { turístico? Porquê? }\end{array}$ \\
\hline $\begin{array}{l}\text { II- Meios de } \\
\text { Comunicação }\end{array}$ & $\begin{array}{l}\text { - Averiguar quais os meios de comunicação } \\
\text { que o poder local utiliza para promover a } \\
\text { imagem do seu concelho como um destino } \\
\text { turístico, e qual consideram ser o mais } \\
\text { importante } \\
\text { - Avaliar a importância que o poder local dá } \\
\text { à Internet para a promoção do seu concelho } \\
\text { como um destino a visitar }\end{array}$ & $\begin{array}{l}\text { 1- Que meios de comunicação é que } \\
\text { o seu município usa para promover a } \\
\text { imagem do seu concelho com um } \\
\text { destino turístico? } \\
\text { 2- Qual considera ser o meio de } \\
\text { comunicação mais importante para a } \\
\text { promoção? Porque? } \\
\text { 3- Que importância dá à Internet para } \\
\text { a promoção do seu concelho? }\end{array}$ \\
\hline $\begin{array}{l}\text { III- Direcção Regional } \\
\text { do Turismo (DRT) }\end{array}$ & $\begin{array}{l}\text { - Identificar o papel da DRT na promoção } \\
\text { dos municípios madeirenses }\end{array}$ & $\begin{array}{l}\text { 1- Como é que a DRT deve } \\
\text { promover a região como destino } \\
\text { turístico para que o sector do turismo } \\
\text { seja alargado a todos os concelhos? }\end{array}$ \\
\hline
\end{tabular}

\section{Internet e Promoção dos Destinos Turísticos}

O surgimento da Internet introduziu profundas mudanças na sociedade. É um meio totalmente abrangente que interage com o conjunto da sociedade, onde expressa os processos, os interesses, os valores e as instituições sociais (CASTELLS, 1999). Com este novo meio de comunicação, a sociedade desvela-se num ambiente simbólico de interfaces, de múltiplas imagens e sons que fazem da virtualidade uma realidade. $\mathrm{O}$ autor realça, ainda, que este novo método de comunicação, que gera virtualidade real, assenta num sistema em que a própria realidade é inteiramente captada, totalmente imersa numa composição de imagens virtuais no mundo do faz-de-conta, no qual as aparências não apenas se encontram na teia comunicadora 
da experiência, mas se transformam na experiência. Segundo ele, o que caracteriza este novo sistema de comunicação (baseado na incorporação de uma rede digitalizada por diferentes modos de comunicação) é a sua capacidade de integração e abrangência de todas as expressões culturais. O espaço, o tempo e as dimensões fundamentais da vida humana são transformados radicalmente por este novo sistema de comunicação. Assim, as sociedades correm o risco de perder o encanto de práticas sociais tradicionais para se inserirem num mundo de imagens auto-construídas e despojadas das suas realidades geográficas. Para este sociólogo, a humanidade está perante um desafio, que é o de aplicar o conhecimento de forma que se desenvolva um mundo predominantemente social. Desta forma, na Internet, a informação representa o principal elemento para a organização social da humanidade (CASTELLS, 1999). Com a Internet a distância geográfica perdeu o seu poder de separação à medida que pessoas de distintos e remotos pontos do planeta podem comunicar de uma forma instantânea. A Internet é um dos instrumentos de difusão e de troca de informação mais valiosos, devido à sua capacidade de estabelecer comunicações rápidas, independentemente do local geográfico em que se encontrem os seus utilizadores (BORGES, 2001).

O turismo é um sector de grande importância económica que está a sofrer uma significativa transformação com a utilização da Internet. Trata-se de um meio que permite uma excelente forma de comunicação entre os utilizadores e os respectivos prestadores de serviços (Lage 2000). A Internet possibilita, hoje, uma disseminação rápida do conhecimento, permitindo às organizações públicas e privadas do turismo não só melhorar a sua eficiência mas, também, oferecer novos produtos e serviços pelos quais os consumidores, através dos mecanismos de mercado, manifestam a sua preferência. “O turismo e a Internet são uma combinação frutífera. O rápido aumento, em capacidade e utilização da Internet em anos recentes, forneceu oportunidades para uma mudança estrutural no desenvolvimento, marketing e criação de serviços de turismo” (COSTA; RITA e ÁGUAS, 2001, p. 125).

O turismo é uma indústria baseada numa informação intensiva (O`CONNOR, 1999). Assim sendo, a Internet é o meio de comunicação mais eficaz que existe para o intercâmbio de informação turística a nível mundial. “A rede pode, de certa forma, facilitar a promoção e a distribuição de produtos turísticos e potencialmente permitir que destinos e empresas turísticas possam competir a um mesmo nível” (LIU, 2000, p. 12). Actualmente, este novo instrumento oferece, para além de outros, dois métodos essenciais para troca de informação que tanto as empresas turísticas como as organizações promotoras de turismo podem utilizar: O correio electrónico e a WWW (World Wide Web). A importância da ferramenta WWW para 
a indústria do turismo pode ser resumida da seguinte forma: “...A World Wide Web oferece uma infra-estrutura para a distribuição global e o fornecimento de informação multimédia de natureza turística. Ela também dá mais poder ao consumidor, através do fornecimento dirigido de produtos que atendem às suas necessidades individuais, diminuindo, assim, a distância entre o consumidor e o destino/oferta, de uma forma interactiva e flexível” (COOPER et al., 2001, p. 461).

No mundo competitivo dos destinos turísticos, a informação que é divulgada aos turistas é fundamental para apoiá-los no seu processo de decisão sobre um destino a visitar. Para além disso, a maioria dos produtos turísticos são serviços intangíveis e, portanto, o turista não o pode “tocar" ou "provar” antes da compra (LIU, 2000). Tal situação, leva as organizações promotoras dos destinos turísticos a proporcionar uma maior quantidade e qualidade de informação para que o turista a possa utilizar no seu processo de decisão. "Uma informação compreensiva, relevante e oportuna é essencial para o processo de decisão dos turistas, mas esta não estava facilmente disponível para os turistas até ao aparecimento da Internet. Com a Internet a quantidade de informação é virtualmente ilimitada e armazenada em web sites, e um número ilimitado de utilizadores pode ter acesso a ela em qualquer momento e desde qualquer parte do mundo” (LIU, 2000, p. 14). Assim sendo, a Internet surgiu como um novo meio de comunicação ideal para a propaganda dos destinos turísticos. A Internet como um novo meio de comunicação proporciona as seguintes vantagens às organizações promotoras do turismo: Pode chegar a um grande número de consumidores em todo o mundo com informação a um custo relativamente baixo; divulga informação mais completa e de mais qualidade em relação à informação de material impresso; pode gerar reservas de forma rápida e fácil; melhora as comunicações e as relações e, finalmente, permite uma redução dos custos na produção e distribuição do material impresso. É um facto que a Internet, enquanto instrumento de promoção para o turismo, é um meio de comunicação que não deve ser ignorado. No entanto, ela não deve ser vista como um “...substituto para outras actividades promocionais, mas sim como um complemento das existentes, o que oferece aos consumidores uma maior possibilidade de escolha e mais uma maneira de fazer reservas” (BRIGS, 1997, p.115).

\section{O Novo Consumidor em Turismo}

O advento da Internet fez com que surgisse um novo perfil de consumidor que, actualmente, está cada vez mais exposto a um conjunto de informações que influem determinantemente no processo da sua decisão, o que o torna mais seguro e exigente no acto de consumo. A Internet 
tem a capacidade de fornecer informações com maior dinamismo, qualidade e economia. Facilita a pesquisa, a organização de uma viagem e multiplica as opções de destinos e possibilidades. "Há alguns anos atrás, as possibilidades de aceder a tal tipo de informações eram quase impossíveis. Um viajante acreditava apenas na agência de viagens, nos folhetos aí disponíveis, num ou noutro relato feito por um amigo ou num livro editado uns anos atrás. A Internet foi o último elo de um processo de desenvolvimento contínuo nas tecnologias da informação, a que temos assistido desde o começo da nossa vida pessoal. Hoje, há uma espécie de ‘faça você mesmo’, organize as suas próprias férias” (SANTOS, 1999, p.1). Com este novo meio de comunicação, o potencial consumidor pode organizar as suas próprias férias, e é capaz de conceber circuitos turísticos que não estão previstos nos planos, por exemplo, de uma agência de viagens. De facto, “A Internet permite aos seus utilizadores o conhecimento prévio de imagens, de lugares e destinos turísticos com elevado grau de detalhamento, embora não substitua o desejo e o consumo das viagens. Como forma de conhecimento é absolutamente pertinente, atendendo a todos os interesses, inclusive de divulgação nas vendas de pacotes de agências, hotéis, parques temáticos, transportes e tantos outros. Mas o consumidor de produtos turísticos não se satisfaz com esta visão, que, pelo contrário, muitas vezes passa a ser um estimulante na decisão final do deslocamento físico para o pólo turístico desejado” (LAGE, 2000, p. 46). Os estímulos atribuídos por este novo meio de comunicação são decisivos para que as informações de outros destinos despertem a curiosidade e o interesse em viajar.

Segundo Molleta e Garcia (2001), as principais vantagens da Internet para os consumidores de turismo estão, essencialmente, no acesso a uma gama de informações on-line; no manuseamento dessas informações; na possibilidade de comparar e confrontar prestadoras de serviços, avaliar preços e outras ofertas. No passado, os turistas confiavam sobretudo nos folhetos impressos e brochuras disponibilizadas pelas agências de viagem. Hoje, através de câmaras web instaladas em hotéis, praias e monumentos ou qualquer outro recurso de atracção turística, os turistas podem observar a situação “real” do destino escolhido. Essa informação até pode ser manipuladora, mas é um facto que “a Internet pode oferecer aos turistas actuais e potenciais informação actualizada sobre o destino em todos os seus aspectos - atracções turísticas, transporte, comodidade, operadores de viagem, compras e instalações de lazer, assim como a sua gente, cultura, história, economia e clima” (LIU, 2000, p.16). Portanto, a Internet, mais propriamente a web, pode apresentar ao potencial turista uma informação minuciosa e actualizada sobre um destino turístico. Por isso, o desejo de conhecer outros 
lugares e outras culturas é cada vez mais estimulado pela Internet. “A ideia de viajar vem penetrando de tal forma na mente do homem moderno que, cada vez mais, se fortalece como uma conquista, um direito, uma possibilidade, um consumo. Pode-se afirmar que a viagem é hoje um dos grandes consumos criados no contexto da sociedade através dos meios de propagação colectiva, sobretudo os meios de comunicação de massa electrónicos” (CORIOLANO, 1998, p.30).

Para um turista cada vez mais exigente, a Internet passou a ser um meio de comunicação essencial e, para as empresas, uma oportunidade de estreitar os laços das suas marcas com os consumidores (BRANDÃO, 2001). Os turistas confiaram durante muito tempo na informação limitada divulgada pelos meios de comunicação tradicionais (jornais, revistas, brochuras, outdoors, televisão, rádio, etc.). Hoje, com a Internet, o consumidor de turismo passou a ter maior acesso à informação e, portanto, o seu poder de comparação aumentou (RAFFOUR, 2002). O controlo da informação passou, de certa forma, a estar nas mãos do consumidor, uma vez que ele decide o que deseja saber, em que momento e em que quantidade de informação.

Enquanto os anúncios de outros veículos de comunicação informam a existência do produto com respectivos benefícios, a web faz o mesmo divulgando informações detalhadas de forma que o usuário reflicta - pense realmente sobre os atributos de sua compra antes de sua efectivação. (...) Este tipo de informação faz com que o destinatário de mensagens pela Web passe a ser considerado um receptor activo, crítico, qualificado e interessado. (LAGE, 2000, p.46)

De facto, a Internet fornece toda aquela informação necessária para que um potencial turista possa tomar a decisão de converter-se em visitante, e seleccionar esse destino frente a outras alternativas. "Se antes, na propaganda tradicional, o anunciante decidia a mensagem e a divulgava nos media, agora quem decide a mensagem que quer ver é o consumidor. No ambiente virtual, é o seu interesse pelo assunto que activa a comunicação e não mais o interesse da empresa em fazer com que ele conheça o seu produto. A linguagem publicitária na rede precisa de um apelo muito maior para atrair a atenção do público. A preocupação com a forma - objectivo máximo do discurso publicitário - deixa de ser soberana. O conteúdo passa a ser tão determinante como a maneira com que ele será apresentado” (BRANDÃO, 2001, p. 3). 


\section{Análise das entrevistas}

$\mathrm{Na}$ análise de conteúdo das entrevistas aos presidentes dos municípios ${ }^{2}$ da Madeira e ao Director da DRT, verificou-se que o poder local e regional atribui uma importância significativa à Internet para a promoção das suas localidades como destino a visitar.

Quadro III - Identificação das Entrevistas

\begin{tabular}{|c|l|}
\hline Entrevistas & \multicolumn{1}{c|}{ Entidades } \\
\hline 1 & Município de S. Vicente \\
\hline 2 & Município de Santa Cruz \\
\hline 3 & Município de Câmara de Lobos \\
\hline 4 & Município de Santana \\
\hline 5 & Município do Funchal \\
\hline 6 & Município de Machico \\
\hline 7 & Município do Porto Moniz \\
\hline 8 & DRT \\
\hline
\end{tabular}

Questionados sobre os meios de comunicação que usam para promover a imagem da sua localidade como um lugar a visitar, a opinião dos entrevistados recaiu sobre os seguintes meios: Jornais e Revistas (E1, E2, E3, E4, E6, E8), Brochuras (E1, E2, E3, E4, E5, E6, E7, E8), Internet (E1, E3, E4, E6, E8), Livros (E5), Televisão (E6 e E8), Rádio (E7). Apesar de só cinco dos entrevistados usar a Internet para a promoção das suas localidades, ela foi considerada por todos os inquiridos como o meio de comunicação mais importante para a promoção do turismo.

A importância da Internet para a promoção do turismo é bem ilustrada na entrevista (1): “A Internet é um instrumento importante para a promoção da nossa região e do nosso concelho. Com ela é possível dar uma maior atenção ao potencial turista, sobretudo, ao nível da informação. Ela pode ser actualizada a qualquer momento. Nos outros meios de comunicação, a informação é limitada e não podemos inserir muita imagem a cores. Para além disso, temos de comprar espaço a um custo bastante elevado. Por outro lado, os press releases sobre eventos que se envia para os meios de comunicação são muitas vezes esquecidos pelos jornalistas. Com a Internet isso já não acontece. Sempre que realizamos eventos procuramos sempre inserir a informação na nossa página”. De facto a Internet como ferramenta de promoção, oferece ao sector turístico a oportunidade de modificar e actualizar a

\footnotetext{
${ }^{2}$ Dos dez municípios, apenas sete participaram nas entrevistas.
} 
informação a custo baixo. Nos outros meios de comunicação (brochuras, folhetos, etc.), não é fácil modificar ou actualizar a informação de uma forma tão rápida. Para além disso, implica custos elevados.

A entrevista (3) realça a capacidade da Internet como uma aproximação entre o potencial turista e a organização promotora: “A Internet possui uma grande capacidade de interactividade. Com ela, há a possibilidade de aceder em tempo real à pergunta/resposta. Recebemos muitos e-mails a solicitar informação sobre eventos no nosso concelho. A informação pode ser mais pormenorizada. O nosso concelho possui muitos roteiros turísticos e, com a Internet, pode-se dar um conhecimento mais pormenorizado sobre esses roteiros”. É óbvio que a Internet constitui um espaço de intensificação dos fluxos informacionais e da interactividade comunicacional. Daí, que assuma uma importância cada vez maior como factor de produção de conhecimento: busca, troca, disseminação e reconstrução da informação. A Internet, com a sua capacidade de interacção, oferece ao consumidor instrumentos para que ele possa obter as informações de que precisa. Ou seja, funciona como uma ferramenta para o turista na busca de informações sobre o local que quer visitar e/ou até mesmo na decisão sobre o destino a visitar.

Para alguns municípios, o aparecimento da Internet faz com que as suas localidades possam ser promovidas em todo o mundo como um verdadeiro destino turístico e um local para ser usufruído durante alguns dias. "Os turistas quando vêm à Madeira limitam-se a visitar os principais pontos turísticos organizados pelos operadores. Muitas vezes os concelhos funcionam só como um local de passagem. A Internet dá-nos a possibilidade de mostrar ao turista que visita a nossa região que ele não deve ficar somente pela cidade do Funchal e visitar os sítios mais importantes. O nosso concelho possui bons atractivos turísticos, serviços adequados, bom entretenimento e, por isso, o turista que visita o nosso concelho pode perfeitamente passar cá dois ou três dias. É nesta perspectiva que a Internet funciona como uma ferramenta imprescindível para nós. Ou seja, divulgar aquilo que temos para oferecer ao turista: o que pode fazer, onde ficar, onde comer e onde ter acesso a informações. Nós temos uma série de actividades turísticas que vão desde os roteiros culturais aos percursos a pé e, muitas vezes, os turistas desconhecem porque não é divulgado pela Direcção Regional do Turismo. E nós não podemos divulgar essa informação de forma pormenorizada porque tem um custo bastante elevado nos outros meios de comunicação. Temos panfletos e brochuras, mas não é suficiente porque são apenas distribuídos em eventos relacionados com o turismo e, portanto, não chega a todo o lado” (Entrevista 6). Antes, a divulgação dos 
destinos das organizações promotoras incrementava-se de forma proporcional ao seu alcance geográfico e a informação era limitada. Com a Internet o âmbito geográfico é irrelevante, a informação é infinita e distribuída em vários formatos: textos, imagens, fotos, gráficos, sons e vídeos. Todas estas características fazem com que as organizações promotoras possam dar a conhecer melhor o seu destino turístico (Informação pormenorizada sobre as atracções turísticas, actividades que os turistas podem realizar, os lugares onde podem alojar-se, etc.).

O Entrevistado (8) enfatiza que a Internet é um “universo de oportunidades” para as organizações promotoras do turismo. Ainda, segundo aquele entrevistado, a Internet "como forma de conhecimento, é bastante pertinente porque atende a todos os interesses do sector público e privado. Com a Internet qualquer pessoa pode aceder a um conjunto vasto de informações que vai desde aos atractivos, ao alojamento e alimentação, do entretenimento ou animação turística às estruturas básicas e de apoio. Temos cerca de 20 mil acessos anuais ao nosso web site, e todos os dias nos solicitam informação. É, portanto, uma excelente fonte de informação para a promoção do destino Madeira. Dá a conhecer a região em qualquer parte do mundo, e o turista real ou potencial fica com uma ideia do que pode visitar, onde se alojar e quais as actividades turísticas que pode praticar”. O entrevistado (4) também realça o papel da Internet na promoção de uma localidade: “Quando se faz publicidade nos outros meios de comunicação, destaca-se apenas o essencial. Divulga-se que temos um património natural, edificado, eventos, boa gastronomia, etc. Mas não há uma descrição pormenorizada dos lugares e daquilo que o turista pode fazer. Portanto, a Internet faz com que toda essa informação básica (informação detalhada sobre cultura, património, localidades adjacentes ao concelho, paisagem, etc.) ajude não só a informar, mas também, a atrair, a seduzir o potencial turista. Para além disso, pode-se fornecer dados sobre os serviços turísticos, transportes e acessibilidades".

O Entrevistado (5) salienta a importância da Internet como "um novo meio de comunicação para a promoção do turismo. Actualmente a Internet está instalada na maioria das empresas e na maioria dos lares. Com uma técnica de utilização bastante acessível, uma capacidade de informar bastante grande e visualmente atractiva, revela-se, sem dúvida, um meio de consulta obrigatório e de promoção por excelência”. No entanto, verificou-se que o web site do respectivo município não possui uma página sobre turismo. Os entrevistados (2) e (7) consideram, também, que a Internet é um “excelente veículo de promoção”, mas os seus municípios ainda não têm um site na Internet. De acordo com o entrevistado (7), "não basta ter um site e depois a informação estar desactualizada. Algumas instituições têm web sites 
que são elaborados por algumas empresas. Depois quando querem actualizar a informação têm de estar sempre sujeitos a essas mesmas empresas. Por isso, queremos primeiro ter os recursos humanos necessários para desempenhar essa função”. Significa isto que a Internet, enquanto um novo meio de comunicação, também tem as suas desvantagens. Ou seja, é necessário formar e sensibilizar os recursos humanos para as novas tecnologias, pois elas exigem novas competências e novos saberes. Todos reconhecem que a Internet tem vantagens em relação aos outros meios de comunicação, mas salientam que é necessário saber tirar proveito dela. Ela surge como uma ferramenta que possibilita o acesso instantâneo à informação sobre destinos turísticos mas é, também, um novo campo de batalha para as organizações promotoras. "Hoje, com as novas tecnologias, a concorrência entre os destinos é cada vez maior. Por isso, temos que ter uma presença na Internet. É necessário convencer o turista com aquilo que melhor se tem para oferecer. Nós sabemos que a Madeira é visitada pela sua beleza natural ao nível da paisagem e, por isso, procuramos realçar sempre esse pormenor. Mesmo a nível de concelhos regionais, queremos que seja o nosso a ser visitado e não outro qualquer. Daí, que procuramos ter uma página de turismo com toda a informação necessária, acompanhada de textos e imagens, sobre o nosso concelho para que os turistas venham usufruir a nossa localidade e não outra” (Entrevista 1).

Todos são unânimes que a promoção das localidades deve passar pelos principais atractivos turísticos. Atente-se por exemplo na entrevista (1): "São as atracções turísticas que fazem com que os turistas visitem o nosso concelho ou a nossa região. Os atractivos naturais (mar, montanha, serra) e culturais (monumentos e tradições populares) são a principal motivação para os turistas visitarem a nossa região. Os visitantes procuram conhecer aquilo que é diferente do seu quotidiano e, portanto, temos que ser originais na nossa promoção. Não devemos promover os serviços turísticos. Essa é uma função dos empresários”. A este propósito, o entrevistado (8) refere que "o turista alemão e inglês procura muito o contacto e a proximidade com a natureza. Por isso, na nossa promoção procuramos sempre mostrar aos turistas potenciais que, uma vez na Madeira, poderão usufruir de belezas raras e naturais. A paisagem natural é riquíssima e, por isso, ela constitui o nosso principal elemento de atracção para o turista. Daí que, desde 1996, passamos a adoptar o slogan "Sinta a Natureza à sua Volta”. O turista poderá apreciar a natureza através da prática de passeios a pé pelas levadas e pelas veredas. Tudo isto aliado ao clima e à excelente oferta de qualidade hoteleira faz com que a região seja um destino de sucesso". 
No que concerne ao papel da DRT na promoção dos concelhos, a maioria dos entrevistados (E1, E2, E3, E4, E6, E7) salienta que o referido organismo deveria, na sua promoção, divulgar informação mais específica sobre os concelhos. Ou seja, uma informação mais detalhada sobre os principais pontos turísticos e a cultura local. Pois, segundo o entrevistado (1), “os turistas que nos visitam são maioritariamente oriundos de centros urbanos e, por isso, a DRT deve ter uma maior preocupação em fazer com que eles conheçam mais o nosso meio rural e as nossas principais atracções turísticas. Deve, por isso, definir estratégias de visitas aos outros pontos da ilha”.

Alguns entrevistados (1), (2), (3), (4) e (6) defendem que a DRT deveria dar mais importância aos atractivos culturais. "Não é só a paisagem que deve ser promovida. Temos uma identidade cultural bastante forte que se manifesta através dos nossos hábitos e costumes. Temos o artesanato (bordado e vimes), o folclore, a gastronomia e os arraiais populares. Tudo isso deve ser mais divulgado para que o turista quando visita a Madeira não se fique só pela paisagem e pelo bom clima. O dar a conhecer os nossos usos e tradições também atrai turistas, gera contactos e faz com que a nossa cultura seja promovida lá fora” (Entrevista 4). De facto, o turismo pode fortalecer a identidade cultural de uma região ou localidade. Por outro lado, há cada vez mais um desejo manifestado pelas localidades em divulgar aos outros as suas raízes ou singularidades específicas. É verdade que hoje se assiste a um processo de globalização onde se procura, cada vez mais, a eliminação das fronteiras que nos separam uns dos outros. Mas, o curioso é que esta nova era marcada pelas novas tecnologias de informação faz com que os países, regiões ou localidades manifestem um desejo crescente de assinalar as suas diferenças culturais.

Ainda a propósito da promoção, o entrevistado (6) refere que "não devemos exigir que seja a DRT a fazer tudo. Os concelhos também devem preocupar-se em fazer uma auto-promoção”. Nesta linha, o entrevistado (8) sublinha que “os presidentes dos municípios têm de pensar mais naquele que visita a Madeira. A promoção também passa por um bom acolhimento e pelo bom cuidado dos nossos espaços públicos. Toda a decisão que eles tomam terá de levar em conta o equilíbrio entre a qualidade de vida da população e o visitante que vem cá. O visitante chega e muitas vezes não conhece a região e, portanto, precisa de uma sinalética dirigida para ele de modo a poder deslocar-se e orientar-se”. Ainda segundo este entrevistado, o que distingue o turismo madeirense de outras ilhas é o factor qualidade. "Não é só o hotel que faz o turista vir à Madeira. É tudo aquilo que nos envolve, ou seja, a qualidade das limpezas dos nossos concelhos: dos espaços verdes que disponibilizamos aos 
turistas, a qualidade dos transportes públicos, etc. Em tudo isto, os presidentes devem ter um papel activo, porque isto também é promoção e faz parte da oferta turística”.

\section{Conclusão}

O turismo envolve um conjunto de relações, influências, motivações, desejos e representações. Permite às pessoas conhecer novos lugares e entrar em contacto com outras culturas. O turismo é um sector de grande importância económica e social que está a sofrer uma significativa transformação com a utilização da Internet.

No sector do turismo, a Internet é reconhecida como uma ferramenta extremamente valiosa para a divulgação dos destinos turísticos. Para além disso, o turista potencial/real pode planear e programar a sua viagem para qualquer lugar do mundo sem sair da sua própria casa. O novo meio de comunicação faz com que os consumidores de turismo aumentem os seus patamares de exigências e de expectativas sobre os destinos turísticos. Através de um simples clique, o potencial turista fica a conhecer a história, cultura, hábitos e costumes de destinos nunca antes imaginados. Todos os lugares à face da terra são apresentados, via Internet, como destinos a ser consumidos. A Internet aguça o apetite pela viagem e, por isso, ela é um meio de comunicação indispensável às organizações promotoras (poder local e regional) de destinos turísticos. Por isso, ao poder local e regional cabe-lhe o papel de sensibilizar o imaginário dos turistas para visitarem as suas comunidades e regiões e não outras.

$\mathrm{Na}$ análise de conteúdo às entrevistas, e através de uma pesquisa aos municípios madeirenses ${ }^{3}$ referenciados na rede, verificou-se que o poder local e a DRT consideram que a Internet é um meio de comunicação fundamental para a promoção turística das suas localidades. Ressaltam ainda que a Internet é um instrumento de comunicação que promove os concelhos da região em todo o mundo, que há a possibilidade de existir uma maior interactividade entre o consumidor, que a informação pode ser divulgada com mais detalhes (inserção de texto, som e imagem) e a custos baixos. Todos os entrevistados afirmam que a Internet tem vantagens em relação aos outros meios de comunicação, mas reconhecem que é preciso saber tirar proveito dela. Ou seja, ela surge como uma ferramenta que possibilita o acesso instantâneo à informação sobre destinos turísticos, mas também é um novo campo de batalha para as organizações promotoras. Para além disso, consideram que é necessário formar e sensibilizar

\footnotetext{
${ }^{3}$ Dos dez municípios madeirenses (Machico, Santana, Funchal, Câmara de Lobos, Ribeira Brava, Calheta, Ponta do Sol, Santa Cruz, Porto Moniz e São Vicente), apenas dois não possuíam web site (Santa Cruz e Porto Moniz). Acrescente-se ainda que o Município do Funchal possuía Web Site, mas não continha uma página sobre turismo. Segundo a entrevista do responsável desse município, a DRT já faz esse papel.
} 
os recursos humanos para as novas tecnologias, pois elas exigem novas competências e novos saberes. De facto, não basta pegar num conjunto de informações e imagens fotográficas, inserir em páginas e enviar para a rede. É preciso saber comunicar de forma eficiente um destino turístico, pois a tomada de decisão sobre um lugar a visitar é muitas vezes condicionada pela imagem que o turista real ou potencial faz desse mesmo lugar. Ou seja, o sucesso de uma região ou localidade não passa somente pela existência de atractivos turísticos, de serviços turísticos ou de infra-estruturas básicas. Passa, também, pela forma como todos esses elementos são divulgados. Se é verdade que a imagem, de certa forma, diferencia os destinos turísticos uns dos outros, então, é necessário que o poder local e a DRT sejam mais eficientes na comunicação do seu destino, via Internet. É preciso transmitir ao potencial turista a ideia de viver uma experiência única em localidades com características singulares.

Através da análise aos sites dos municípios referenciados na rede, verificou-se que tanto o poder local como a DRT apresentam algumas deficiências na promoção da sua localidade ou da sua região como um destino turístico. Assim, aconselha-se ao poder local e à DRT a adaptarem-se à Internet se querem de facto atrair mais visitantes para o seu destino. As novas tecnologias fazem com que a competitividade entre os destinos turísticos aumente de dia para dia, e por isso, quem não souber comunicar bem o seu destino, via Internet, corre o risco de ser superado pela concorrência. Saliente-se que um site turístico só é apelativo para os consumidores se apresentar as seguintes características:

$\diamond$ Homepage - A aparência de uma homepage é crucial para persuadir o turista real ou potencial. Há características que são fundamentais numa homepage para prender a atenção do consumidor: lista de conteúdos do site, a marca do destino, uma breve descrição do destino turístico, fotos, clima e disponibilização dos idiomas principais, etc. De uma forma geral, uma homepage deverá ser simples, ou seja, ter um design claro. Deverá, através da disponibilização da informação, transmitir uma boa imagem do destino.

४ Informação turística oferecida nos sites - A forma como a informação sobre o destino é divulgada, fará com que o utilizador opte ou não pela selecção desse mesmo destino. O turismo é uma indústria vinculada à informação. Os produtos e serviços turísticos são bens intangíveis e, por isso, precisam de uma informação fidedigna, actualizada e pormenorizada para a sua promoção e, sobretudo, para a sua óptima comercialização. Para os turistas é importante o acesso que eles têm à informação. Quanto mais longe é a distância entre o destino e o turista, mais necessidade há de informação por parte dele. 
Assim sendo, é necessário que as entidades locais possuam nas suas páginas informação essencial sobre os seus municípios como destinos turísticos a usufruir: Como chegar ao destino; o que visitar no destino; onde alojar-se; que actividades e acontecimentos é que o destino oferece; o seu clima e a sua história. Como ferramenta de promoção, a Internet oferece às entidades locais a facilidade de inserção de toda esta informação, bem como a sua modificação ou actualização.

$\diamond$ Características do site - Um site turístico deve ser compreensível e ter uma navegabilidade fácil. Deverá ter mapas, estar disponível em vários idiomas e ter possibilidades de zona de interacção com os visitantes. Só assim fará com que a visita seja uma experiência agradável para o visitante que, depois, até o poderá recomendar a outros potenciais turistas.

Conclui-se que a Internet está a conquistar um papel importante na promoção dos destinos turísticos. No caso particular da ilha da Madeira (que há muito conquistou uma imagem de marca), a utilização da Internet tem vindo, progressivamente, a desempenhar uma função crucial na divulgação da oferta madeirense. Todavia, apesar da importância que os detentores do poder político dão a tal instrumento promocional, torna-se necessário melhorar a qualidade e diversidade dos sites e das páginas turísticas, tornando a pesquisa na web cada vez mas atractiva através de interacção criativa, motivadora, utilitária e eficaz. Note-se que quem possuir uma boa estratégia de comunicação na divulgação da informação terá maiores vantagens na opção do turista, uma vez que há tendência para um melhor conhecimento e uma maior capacidade de selecção e escolha. Se a comunicação for deficitária, a Internet pode servir para que o turista opte por outra localidade, tornando-a um mecanismo valorizador de outros concorrentes. Por isso, às entidades promotoras do turismo cabe-lhes um novo desafio: saber comunicar o seu destino a este novo perfil de turista que, com as novas tecnologias de informação e comunicação, são cada vez mais exigentes devido ao acesso que têm à informação.

\section{Referências Bibliográficas}

ALMEIDA, João Ferreira e PINTO, José Madureira. 1995. A investigação nas ciências sociais. Lisboa: Presença..

BELL, Judit. 1997. Como realizar um projecto de investigação. Lisboa: Gradiva.

BORGES, Maria do Rosário P. da Silva. 2001. A Internet como fonte de informação de apoio à actividade docente no ensino superior de Turismo em Portugal. Dissertação de Mestrado em Gestão de Informação, Universidade de Aveiro. 
BRANDÃO, Vanessa Cardozo. 2001. Comunicação e marketing na era digital: a Internet como mídia $e$ canal de vendas. Comunicação apresentada no XXIV Congresso Brasileiro de Ciências da Comunicação - Campo Grande. $\quad$ Disponível <http://www.intercom.org.br/intercom/intercom.shtml>. Acesso em 23 ago 2003.

BRIGS, Susan. 1999. Marketing para o turismo no século XXI. Lisboa: Edições CETOP.

BUHALIS, Dimitrios, 2000, Tourism and information technologies: Past, Present and Future. Tourism Recreation Research. Vol. 25 (1). p. 41-58;

CASTELLS, Manuel. 1999. A sociedade em rede. 2. Ed., Vol. 1. São Paulo: Paz e Terra.

COOPER, Chris; GILBERT, David; FLETCHER, John; WANHILL, Stephen. 2001. Turismo: princípios e prática. São Paulo: Bookman.

CORIOLANO, Luzia Neide M. T. 1998. Do local ao global: o turismo litorâneo cearense. Campinas: Papirus.

COSTA, Jorge; RITA, Paulo; ÁGUAS, Paulo. 2001. Tendências internacionais em turismo. LisboaPorto-Coimbra: Lidel

LAGE, Beatriz H. G. 2000. Comunicação de massa e turismo. Turismo: teoria e prática. São Paulo: Atlas.

LIU, Zhenhua. 2000. Internet tourism marketing: potential and constraints. Fourth International Conference Tourism in Southeast Asia \& Indo-China: Development, Marketing and Sustainability. The Scottish Hotel School. University of Strathclyde, UK.

MARUJO, Maria Noémi N. V. 2004. Turismo: meios de comunicação e promoção: o caso da Madeira. Dissertação de Mestrado em Sociologia, Universidade de Évora.

MOLETTA, Vania B. Florentino e GARCIA, Roslaine Kovalczuk de Oliveira. 2001. Turismo: tendências e novas tecnologias. Porto Alegre: SEBRAE/RS.

O’CONNOR, Peter. 1999. Electronic information distribution in tourism and hospitality. Oxford: CAB International Publishing.

RAFFOUR, Guy. 2002. L'impact des nouvelles technologies de l'information et de la communication dans le secteur du tourisme: enjeux et recommendations. Disponível em: <http://www.raffourinteractif.fr>. Acesso em 11 mai. 2002.

SANTOS, Rogério. 1999. As tecnologias de informação e o turismo. Recensio. Disponível em: <http://bocc.ubi.pt/pag/santos-rogerio-media-turismo.html>. Acesso em 21 fev. 2002.

SHELDON, Pauline J. 1993. Destination information systems. Annals of Tourism Research. vol.20, $\mathrm{n}^{\circ}$ 4, p. 633-649.

SWARBROOKE, John e HORNER, Susan. 2002. O comportamento do consumidor no turismo. São Paulo: Aleph.

\section{Recebido: 10/10/2007(1 ${ }^{a}$ versão) $29 / 03 / 2008$ (2 $2^{\text {a }}$ versão) Aprovado: 11/04/2008}

